\title{
Application of best-worst method in evaluation of medical tourism development strategy
}

\author{
Farzaneh Abouhashem Abadi $^{a}$, Iman Ghasemian Sahebi ${ }^{\mathbf{b}^{*}}$, Alireza Arab ${ }^{\mathrm{c}}$, Abbas Alavi ${ }^{\mathrm{d}}$ and Hedieh \\ Karachi $^{\mathrm{e}}$
}

${ }^{a}$ MSc. in Tourism Marketing Management, Department of Management, University of Tehran, Tehran, Iran

${ }^{b}$ PhD student of Operation Management, Department of Management, University of Tehran, Tehran, Iran

${ }^{c} P h D$ student of Operations research, Department of Management, university of Tehran, Tehran, Iran

${ }^{d}$ PhD student of Operations Research, Department of Management, University of Tehran, Tehran, Iran

${ }^{e}$ MSc. in business administration, Department of Management, university of Tehran, Tehran, Iran

\begin{tabular}{l}
\hline C H R O N I C L E \\
\hline Article history: \\
Received Febryary 16, 2017 \\
Received in revised format: \\
February 22, 2017 \\
Accepted April 12, 2017 \\
Available online \\
April 15 2017 \\
\hline Keywords: \\
Medical tourism industry \\
Strategic planning \\
Best worst method \\
SWOT \\
Yazd Province
\end{tabular}

\section{Introduction}

Today, tourism is considered as the largest and most diverse industry in the world which, as the main source of income and employment, plays an important role in countries' economic growth (Ganguli \& Ebrahim, 2017). Given the significant capacities in Iran, especially Yazd province, climate and weather conditions, and low treatment cost compared to many countries around the world and in contrast, the need to develop tourism industry and currency income, Iran does not have a suitable position in the

\begin{abstract}
Medical tourism industry is an international phenomenon, which most of medical tourists for some reasons such as high costs of treatment, long waiting queues, lack of insurance and lack of access to health care in the origin country, travel long distances to benefit from health care services of destination country. Given the competitive nature of this industry, most countries are designing practical and legal services and planning for their development. For this purpose, this study has been conducted to develop a strategic planning framework for development of medical tourism industry in Yazd province of Iran; because in recent years Yazd has recognized as the health pole by patients in developing countries. In sum, emphasizing on servicing, enhancing and developing specialized treatment centers, has attracted patients from center, south and east of the country as well as Middle East and Central Asia countries. The dominant approach in this study is developmental - practical and also the research method is descriptive, analytical and survey. In order to analyzing the data, the SWOT model and best-worst techniques have been used. In the following, after identifying strategic position of Yazd province in terms of medical tourism industry, the related strategies were formulated and practical results were presented.
\end{abstract}

* Corresponding author. Tel: +98 9119498991

E-mail address: iman.ghasemian@ut.ac.ir (I. Ghasemian Sahebi)

(C) 2017 Growing Science Ltd. All rights reserved.

doi: $10.5267 /$ j.dsl.2017.4.002 
global tourism industry. Even though there has been little information about the motivations of medical tourists in choosing travel destination (Cormany \& Baloglu, 2011), but previous studies show that different types of medical tourism are performed with this arrangement, firstly, choosing treatment destination that its effectiveness and usefulness of that destination has been perceived by the patient, then, organizing for travel and desired medical care and finally, a trip to an unfamiliar location (Dalstrom, 2013). The growing trend of traveling abroad in order to get health care is usually known as medical tourism and it is expected that this trend will continue to its exponential growth up to the next 10 years (Ganguli \& Ebrahim, 2017). The specific characteristics of each country such as its stable political environment, reliable legal policies, infrastructures, appropriate economic conditions are effective in selecting tourist's destination (Smith \& Forgione, 2007). Currently, the main causes of the patient's travel to Iran relates to the quality of health services, low drug and care costs compared with other countries of the region, access to health services and modern and advanced equipment, presence of specialists, existence of skilled experts in the field of health in Iran, similar culture and language and lack of equipment and experts in most origin countries. Medical tourism is a national strategy towards increasing the national income as well as an arm for national security(Khan \& Alam, 2014). Although medical tourism has great potentials in Yazd province, but it faces with several challenges and obstacles in this area. Yazd Province is dominant in some fields, such as infertility treatment and heart surgery, not only in Iran but also in the Middle East and the world. This province has a Research and Clinical Center at the level of international standards. Patients from different cities of the country and the Middle East travel to this province to be treated. Because of the importance of medical tourism in the global economy as well as Yazd's capabilities in this industry, it seems necessary that the strategic planning and strategy development in the field of health tourism and development of this industry needs to be examined further. The aim of this paper is to explain appropriate strategies for developing medical tourism industry in Yazd province. Medical tourism is a new subject and studies show that much research has not been conducted in this field in Iran.

\section{2. literature review}

\subsection{Strategic planning}

Although over two decades of the first time that the strategic planning was introduced in management literature, passes but this concept has not lost its value and validity. Studies conducted by Yuksel and Deviran (2008) showed that the strategic planning has been known as the best and most widely used management tool by organizations and 80 percent of organizations surveyed have used this management technique (Yüksel \& Dağdeviren, 2007).

Strategic planning from the perspective of different scholars has different definitions and the most important definition is as follows: strategic planning is a set of theories, concepts, procedures and tools that along with complementary tools and methods have been designed to help managers and planners for thinking, planning and strategic action. In other words, strategic planning can be defined prospectively and decision making in the present by taking into consideration its future consequences (Dereli, 2007; Stonehouse \& Pemberton, 2002). The SWOT method as the most common technique identifies effective factors and analyzes strengths, weaknesses, opportunities and threats. In fact, SWOT analysis intends to maximize strengths and opportunities and minimize threats and convert weaknesses into strengths and use points associated with the opportunities in order to reduce internal weaknesses and external threats (Arslan \& Er, 2008).

\subsection{Medical Tourism}

Medical tourism includes any trip for health promotion and as one of the aspects of tourism, and helps to sustainable development and the mobility of country's economy (Beladi et al., 2015). Because this industry is low-cost and high-income, many developing countries have focused on this part of industry and have planned for it. Accordingly, health care is considered as a product that patients as aware consumers can choose. This is why cheaper medical alternatives which are available abroad cause that 
people have more freedom in using health care (Kangas, 2010). It is worth noting that until recently travel to receive medical treatment was from less developed countries to the more developed countries (Crooks et al., 2011); but with the recent transformations in the field of medical trips, which its reason is that traveler's travel from developed countries to less developed countries has increased, this trend was reversed and in response to the passengers' growing demand, the number of destinations providing medical services have been expanded to more than 50 countries in the world (Woodman, 2009).

Currently, because this industry is low cost and high income and in order to enhance the structure of country's health and therapy, many of the countries interested in tourism development have focused on this part of industry and have planned for it (Garcia \& Besinga, 2006). Because of advantages such as lower cost of specialized medical staff and hospitals with modern and advanced equipment, Iran could be very successful in the field of medical tourism; but to take advantage of its capabilities in this area, it is faced with challenges (Crooks et al., 2011). Poor coordination among organizations of medical tourism, lack of a comprehensive system for collecting data relating to medical tourists' arrival to Iran, inefficiency of notification system regarding Iran's capabilities in Medical Tourism and lack of required infrastructure for the development of this industry are of the main reasons that have caused the medical tourism industry has not a desirable position in Iran.

Yazd Province for its effective contribution to the medical tourism industry faces with many challenges which some of them include: lack of a regular program for medical tourism, government' inefficient support of medical tourism, basic and health infrastructure requiring improvement, lack of standardization of health care costs and credit allocation to hospitals, low effective intersectional collaboration at the macro level, low intersectional collaboration at the operational level, low development of professional human resources in health sector, promoting Yazd name as the medical tourism pole in the region and world, lack of a coherent and effective marketing for medical tourism, lack of transferability of insurance coverage for medical tourists, lack of effective medical liability insurance coverage, lack of registration system, control and survey of medical tourists, and lack of a responsiveness system to dissatisfied medical tourists.

Given the discussed issues, in order to achieve successful development and management, tourism planning at all levels is essential. The experience of many tourist areas in the world has proved that in long-term, planning for tourism development may include benefits without causing major problems and lead to maintain market satisfactory (WTO, 2008). Planning for countries that still are not faced with a considerable amount of tourists provides essential guidelines to expand it. Planning in areas with already limited tourism is needed for the revitalization of this areas and its future success (WTO, 2008). In this study, a greater emphasis will be on formulating a strategy by examining internal and external factors. Because in recent years, province Yazd has had significant improvements in terms of both manpower and equipment and now it is considered as one of the major treatment poles in Iran.

Several studies in the field of medical tourism inside and outside the country have been done. Kazemi (2007) in his research named factors affecting in attracting medical tourism in Iran and states that social security, having global standards in health centers as well as medical equipment and issuing treatment visas are the most important factors affecting the development of this industry in Iran. Sadr Momtaz and Agha Rahimi (2010) in a research named medical tourism industry in Iran believe that strategies for development, development of general infrastructure, development of human recourses, development of information and marketing system and product development are of the most important factors affecting the development of medical tourism in Iran and the Iranian government to develop medical tourism should take into account all the factors affecting the medical tourism industry and by creating a comprehensive and coordinated program promotes the country's medical tourism industry. Jaafari (2008) in his research examines the current situation of medical tourism in Iran and concludes that Iran faces with challenges in basic and health infrastructure, government's sufficient supports, having a compiled program for development of medical tourism, intersectoral participation and coordination in macro and operational levels, having centers with international reputation providing 
health services, integrated promotion and marketing; and if Iran intends to have a good share in medical tourism, market must act in order to cope with these challenges. A research has examined the situation of medical tourism in Shiraz. The results of Goudarzi et al. (2014) showed that the price of medical and tourism services; the quality of medical and tourism services, culture, health and tourism facilities and equipment, and information and communication technology are of factors affecting the development of medical tourism in Metropolis Shiraz. Therefore, in order to develop this industry, it is necessary to clarify the price of medical and tourism services, improve the quality of health care and tourism services, promote tourist attraction culture, apply health and tourism facilities and equipment with high technology and international standards and use information technology in the fields of medicine and tourism to use the benefits of this industry to create jobs and benefit the country. Investigation of research conducted by the researchers showed that so far no study has examined the strategies of developing medical tourism comprehensively. Also, the ranking of developed strategies by hierarchical fuzzy approach is another innovation of this research which in the following will be described in details.

\section{Research methodology}

\section{1. research approach}

This study in terms of goal is practical and in terms of data collection method is "descriptive exploratory" conducted using SWOT matrix and intends to formulate a strategy to develop medical tourism in Yazd province.

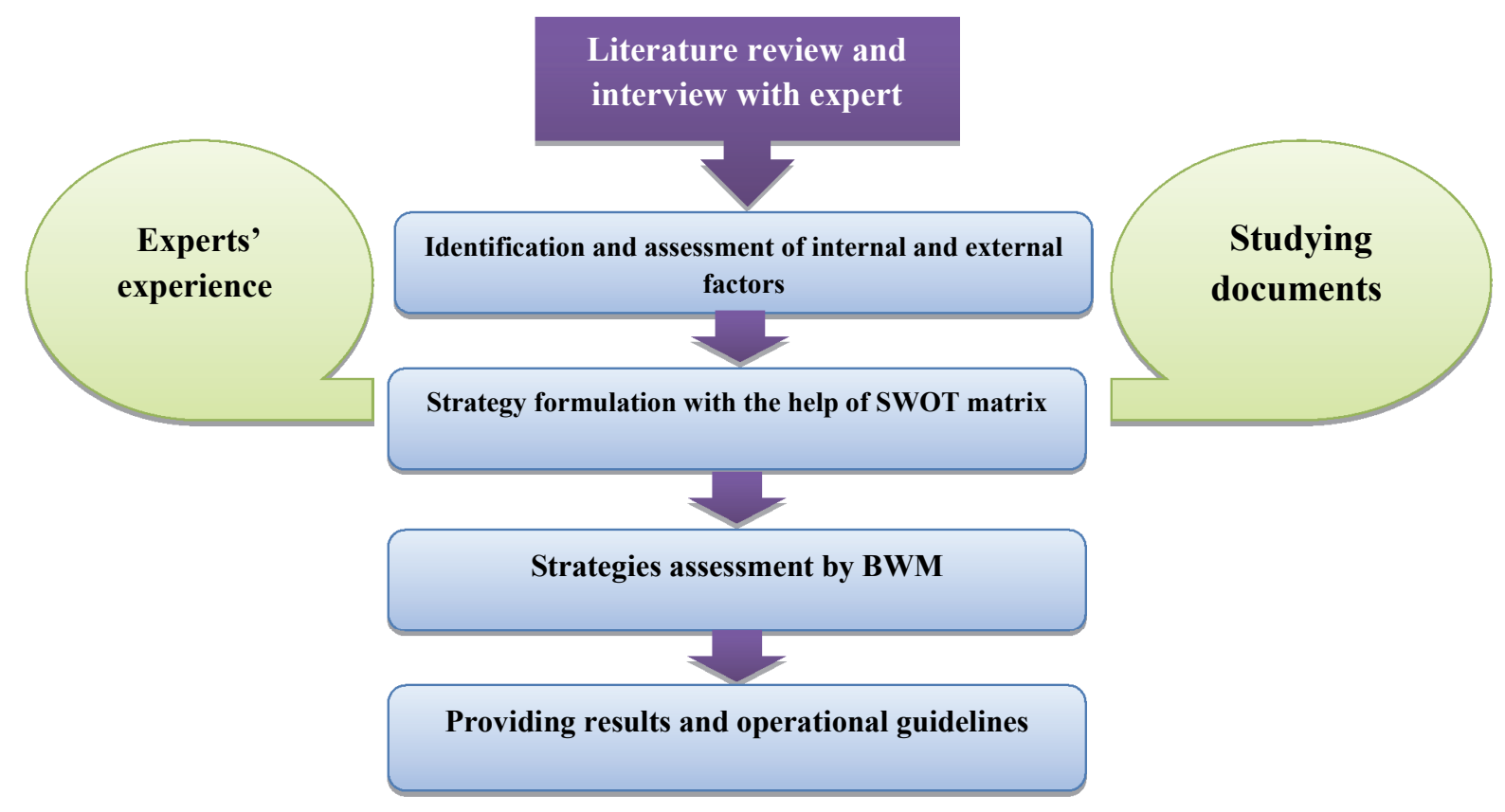

Fig. 1. Research framework.

Preparing a questionnaire is of field methods to collect required data. Also, studying books and articles in the field of strategy formulation and internet sources are considered as library-based methods for data collection. Selection of the best strategies can be viewed as a multi-criteria decision making (MCDM) problem and an extensive evaluation of criteria, must be considered in the ranking process of strategy evaluation (Chaghooshi et al., 2016). Hence, information obtained in this study was analyzed by using tools such as internal and external factors evaluation matrix, SWOT matrix, and bestworst method(BWM). Fig 1 shows the research framework. Moreover, this research took advantage of 7 experts' opinions who had superb experience in field of medical tourism. 


\subsection{The Best Worst Method (BWM)}

BWM is a Comparison-Oriented MCDM method that compares the best criterion to the other criteria and all the other criteria to the worst criterion. The goal is to find the optimal weights and consistency ratio through a simple linear optimization model constructed by the comparison system (Rezaei et al., 2016; Ghaffari et al., 2017). In the literature, some papers utilized this novel MCDM approach. Below is a description of the steps of BWM to calculate the weight of the criteria(Rezaei, 2015a; Rezaei, Wang, \& Tavasszy, 2015; Mohaghar et al., 2017):

1) Determine the set of decision criteria $\left\{c_{1}, c_{2}, \ldots, c_{n}\right\}$ by decision-makers.

2) Determine the best and the worst criteria to be used for the decision environment:

In this step, decision-makers choose the best and the worst criteria among the set of criteria identified in Step 1 from their perspective. The best criteria represent the most important criteria and the worst criteria are the least important criteria for the decision.

3) Determine the preference of the best criteria over all the other criteria:

A number between 1 and 9 (1: equally important, 9: extremely more important) is used to indicate this value. The resulting Best-to-Others (BO) vector would be as $A_{B}=\left(a_{B 1}, a_{B 2}, \ldots, a_{B n}\right)$, where $a_{B \mathrm{j}}$ indicates the preference of criteria $\mathrm{B}$ (best criteria) over criteria $\mathrm{j}$ and $a_{B \mathrm{~B}}=1$.

4) Determine the preference of each of the other criteria over the worst criteria:

A number between 1 and 9 is assigned to this case as well. The Others-to-Worst vector would be as $A_{W}=\left(a_{1 W}, a_{2 W}, \ldots, a_{n W}\right)^{T}$, where, $a_{\mathrm{j} W}$ indicates the preference of the criteria $j$ over the worst criteria $\mathrm{W}$ and $a_{\mathrm{WW}}=1$.

5) Find the optimal weights $\left(w_{1}^{*}, w_{2}^{*}, \ldots, w_{n}^{*}\right)$ :

Solving the problem (1) will result in the optimal weights for the criteria. To determine the optimal weights of the criteria, the maximum absolute differences $\left\{\left|w_{B}-a_{B j} w_{j}\right|,\left|w_{j}-a_{j w} w_{w}\right|\right\}$ for all $j$ should be minimized.

$$
\begin{aligned}
& \min _{\max _{j}}\left\{\left|\frac{w_{B}}{w_{j}}-a_{B j}\right|,\left|\frac{w_{j}}{w_{w}}-a_{j w}\right|\right\} \\
& \text { s.t. } \\
& \sum_{j} w_{j}=1 \\
& w_{j} \geq 0 \text {, for all } j
\end{aligned}
$$

This model can be solved by transferring it to the linear programming formulation (2) (Rezaei, 2015b):

$$
\begin{aligned}
& \min \xi \\
& \text { s.t. } \\
& \left|w_{j}-a_{j w} w_{w}\right| \leq \xi, \text { for all } j \\
& \sum_{j} w_{j}=1 \\
& w_{j} \geq 0, \text { for all } j
\end{aligned}
$$

By solving this problem the optimal weights $\left(w_{1}^{*}, w_{2}^{*}, \ldots, w_{n}^{*}\right)$ and the optimal value of $\xi^{*}$ are obtained. $\xi^{*}$ is defined as the consistency ratio of the comparison system. It means that the closer $\xi^{*}$ is to a zero value the more consistent the comparison system provided by the decision makers. Eq. (3) is used to check the consistency of the comparisons (Rezaei et al., 2016): 
Consistency Ratio $=\frac{\xi^{*}}{\text { Consistency Index }}$

The consistency index can be retrieved from Table 1. The lower the consistency ratio, the higher the reliability of the comparisons.

Table 1

Consistency index table (Rezaei, 2015b)

\begin{tabular}{cccccccccc}
\hline $\boldsymbol{a}_{\boldsymbol{B} W}$ & $\mathbf{1}$ & $\mathbf{2}$ & $\mathbf{3}$ & $\mathbf{4}$ & $\mathbf{5}$ & $\mathbf{6}$ & $\mathbf{7}$ & $\mathbf{8}$ & $\mathbf{9}$ \\
\hline Consistency index & 0.00 & 0.44 & 1.00 & 1.63 & 2.30 & 3.00 & 3.73 & 4.47 & 5.23 \\
\hline
\end{tabular}

\section{Results}

\section{1. strengths, weaknesses, opportunities and threats of tourism industry}

The exact identification of the current position of the medical tourism industry in Yazd Province is a key factor in planning and effective implementation of development strategies.

\section{Table 2}

Strengths, weaknesses, opportunities and threats to medical tourism industry in Yazd province

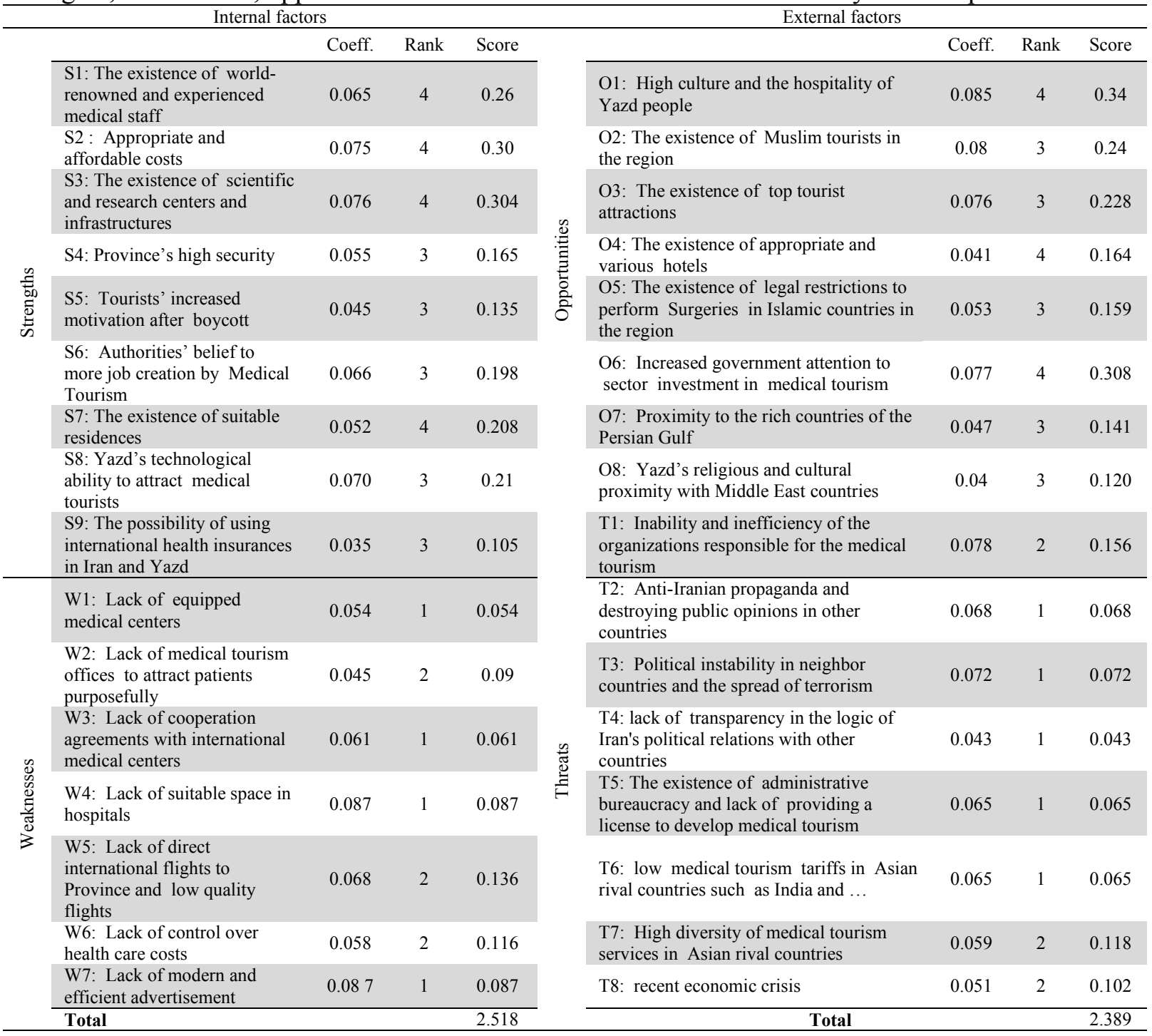


Then these factors were assessed to obtain the point of this industry in the use of internal and external factors. Table 2 shows the strengths, weaknesses, opportunities and threats of tourism industry in Yazd Province with their points. For this purpose, some questionnaires were designed and distributed by the researcher and then internal and external determinant factors of medical tourism industry in Yazd Province (strengths and weaknesses and opportunity and threat) were prepared.

Table 3

SWOT matrix of medical tourism industry development in Yazd Province

\begin{tabular}{|c|c|c|}
\hline SWOT matrix & $\begin{array}{l}\text { Weakness } \\
\text { W1: Lack of equipped medical } \\
\text { centers } \\
\text { W2: Lack of medical tourism } \\
\text { offices to attract patients } \\
\text { purposefully } \\
\text { W3: Lack of cooperation } \\
\text { agreements with international } \\
\text { medical centers } \\
\text { W4: Lack of suitable space in } \\
\text { hospitals } \\
\text { W5: Lack of direct international } \\
\text { flights to Province and low quality } \\
\text { flights } \\
\text { W6: Lack of control over health } \\
\text { care costs } \\
\text { W7: Lack of modern and efficient } \\
\text { advertisement }\end{array}$ & $\begin{array}{l}\text { Strength } \\
\text { S1: The existence of world-renowned and } \\
\text { experienced medical staff } \\
\text { S2: Appropriate and affordable costs } \\
\text { S3: The existence of scientific and research } \\
\text { centers and infrastructures } \\
\text { S4: Province's high security } \\
\text { S5: Tourists' increased motivation after } \\
\text { boycott } \\
\text { S6: Authorities' belief to more job creation } \\
\text { by Medical Tourism } \\
\text { S7: The existence of suitable residence } \\
\text { S8: Yazd's technological ability to attract } \\
\text { medical tourists } \\
\text { S9: The possibility of using international } \\
\text { health insurances in Iran and Yazd }\end{array}$ \\
\hline $\begin{array}{l}\text { Opportunity } \\
\text { O1: High culture and the hospitality of } \\
\text { Yazd people } \\
\text { O2: The existence of Muslim tourists } \\
\text { in the region } \\
\text { O3: The existence of top tourist } \\
\text { attractions } \\
\text { O4: The existence of appropriate and } \\
\text { various hotels } \\
\text { O5: The existence of legal restrictions } \\
\text { to perform Surgeries in Islamic } \\
\text { countries in the region } \\
\text { O6: Increased government attention to } \\
\text { investment in medical tourism sector } \\
\text { O7: Proximity to the rich countries of } \\
\text { the Persian Gulf } \\
\text { O8: Yazd's religious and cultural } \\
\text { proximity with Middle East countries } \\
\text { Threat } \\
\text { T1: Inability and inefficiency of the } \\
\text { organizations responsible for the } \\
\text { medical tourism } \\
\text { T2: Anti-Iranian propaganda and } \\
\text { destroying public opinions in other } \\
\text { countries } \\
\text { T3: Political instability in neighbor } \\
\text { countries and the spread of terrorism } \\
\text { T4: lack of transparency in the logic of } \\
\text { Iran's political relations with other } \\
\text { countries } \\
\text { T5: The existence of administrative } \\
\text { bureaucracy and lack of providing a } \\
\text { license to develop medical tourism } \\
\text { T6: low medical tourism tariffs in } \\
\text { Asian rival countries such as India,... } \\
\text { T7: High diversity of medical tourism } \\
\text { services in Asian rival countries } \\
\text { T8: Recent economic crisis }\end{array}$ & $\begin{array}{l}\text { SO strategy } \\
\text { STR1: Focus on performing } \\
\text { surgeries which are forbidden in } \\
\text { countries of the region (S1, S3, O5, } \\
\text { O7) } \\
\text { STR2: Making a pattern from work } \\
\text { method of leading countries of this } \\
\text { industry in Asia (S1, S2, S5, O6) } \\
\text { STR3: Providing telemedicine } \\
\text { technologies in province's hospitals } \\
\text { regarding tourist attraction (S2, S3, } \\
\text { S6, S8, O2, O8) } \\
\text { ST strategy } \\
\text { STR7: Holding international } \\
\text { exhibitions and conferences in order } \\
\text { to present capabilities of Yazd } \\
\text { tourism industry (S4, S6, T3, T2, } \\
\text { T6) } \\
\text { STR8: Creating specific medical } \\
\text { tourism websites in various } \\
\text { languages (S3,S5,S7,T2,T5,T7) }\end{array}$ & $\begin{array}{l}\text { WO strategy } \\
\text { STR4: Utilizing investors of private section } \\
\text { and supporting them (W2, W7, O6) } \\
\text { STR5: Configuring strategic council of } \\
\text { medical tourism in Yazd Province (W2, W5, } \\
\text { W6, O6, O8) } \\
\text { STR6: Creating medical tourism marketing } \\
\text { centers for attracting target countries (W2, } \\
\text { W3, W7, O1, O3, O6) } \\
\text { WT strategy } \\
\text { STR9: Making traffic routs to the province } \\
\text { safe and constructing proper transport } \\
\text { infrastructure (W5, T1, T3, T8) } \\
\text { STR10: Enacting consistent laws for } \\
\text { attracting medical tourists (W3, W4, W6, T1, } \\
\text { T6, T7) } \\
\text { STR11: Enacting legislations in field of } \\
\text { developing and amending managerial } \\
\text { institutions and applying specialized } \\
\text { management (W4, W6, T1, T2, T5, T8) }\end{array}$ \\
\hline
\end{tabular}


Table 3 shows the formulated strategies to develop medical tourism industry in Yazd Province in the form of SWOT matrix.

\subsection{SWOT matrix formation and formulation of development strategies}

The process of examining and adopting the best choice is largely based on subjective decisions of strategy designers. So that the designers pay attention to series of attractive and applicable strategies which can be managed. Hence, after the identification and assessment of internal and external environment, the researcher based on the strengths, weaknesses, opportunities and threats provides and formulate the most appropriate strategies to implement in SWOT matrix.

\subsection{Formulated Strategies Assessment}

In this step, BWM which was explained in section 3.2 utilized to obtain importance weights of formulated strategies to development of medical tourism (FSDMT).

\section{Determination of the Strategies set}

The Strategies set is determined on the basis of SWOT results as shown in the Table 3.

\section{Determination of the best and the worst Strategy}

The second step in the BWM is the determination of the best and the worst strategy. The best strategy is the one selected by each respondent as the most important FSDMT, while the worst strategy is the one which is the least important FSDMT based on the opinion of each expert. Experts of this research selected creating medical tourism marketing centers for attracting target countries (STR6) as the best strategy and utilizing investors of private section and supporting them (STR4) as the worst strategy, respectively.

\section{Determination of the preference of the best strategy over all others}

This step consists of identifying the preferences of the best strategy from over all other strategies. This data gained by using BWM special questionnaire. The experts are asked to compare their selected best strategy to each of the other strategies and state their preference by using a value between 1 and 9. A score of 1 implies an equal importance over the other strategies. A score of 9 implies the most important strategy is extremely more preferred to the other strategies. Then by calculating Arithmetic mean of the 7 expert's questionnaires, aggregated BO vector constructed, which illustrated in Table 4.

Table 4

Strategies of BO Vector

\begin{tabular}{llllllllllll}
\hline Best strategy & STR1 & STR2 & STR3 & STR4 & STR5 & STR6 & STR7 & STR8 & STR9 & STR10 & STR11 \\
\hline STR6 & 7.8 & 5.3 & 4.9 & 8.5 & 1.7 & 1 & 6.2 & 4.1 & 3.4 & 2.6 & 7.1 \\
\hline
\end{tabular}

\section{Determination of the preference of all strategies over the worst strategy}

This step is similar to the previous step, but in this step, the experts are asked to state their preferences of all other strategies over the least important strategy. Similarly to the previous step, a value between 1 and 9 is used. Then by calculating Arithmetic mean of the10 expert's questionnaires, aggregated Others-to-Worst (OW) vector constructed, which illustrated in Table 5.

Table 5

Strategies OW Vector

\begin{tabular}{llllllllllll}
\hline $\begin{array}{l}\text { Worst } \\
\text { stratgey }\end{array}$ & STR1 & STR2 & STR3 & STR4 & STR5 & STR6 & STR7 & STR8 & STR9 & STR10 & STR11 \\
\hline SRT4 & 2.4 & 4.6 & 5.2 & 1 & 7.9 & 8.5 & 4.3 & 5.8 & 6.5 & 7.1 & 3.4 \\
\hline
\end{tabular}




\section{Determination of the FSDMT weights}

The weights of FSDMT are calculated with a linear model (2) of BWM. By solving this linear model, optimized values of FSDMT weights and $\xi^{*}$ can obtain. This results showed in Table 6 . As can be seen from this results, in this case, 'Creating medical tourism marketing centers for attracting target countries (STR6)', 'Configuring strategic council of medical tourism in Yazd Province (STR5)' and 'Enacting consistent laws for attracting medical tourists (STR10)' are the most important FSDMT and, 'Enacting legislations in field of developing and amending managerial institutions and applying specialized management (STR11)', 'Utilizing investors of private section and supporting them (STR4)' and 'Focus on performing surgeries which are forbidden in countries of the region (STR1)' are the least important FSDMT respectively. As shown in Table 6, the comparisons show a high consistency value of close to zero (the consistency ratio for strategies comparisons obtained 0.0128 ).

Table 6

FSDMT weights

\begin{tabular}{llllll}
\hline Strategy & Weight & Rank & Strategy & Weight \\
\hline STR1 & 0.04108164 & 9 & STR7 & 0.05168336 \\
STR2 & 0.06045978 & 7 & STR8 & 0.07815532 \\
STR3 & 0.06539527 & 6 & STR9 & 0.09424613 \\
STR4 & 0.02304196 & 10 & STR10 & 0.1232449 \\
STR5 & 0.1884923 & 2 & STR11 & 0.01605260 \\
STR6 & 0.2581468 & 1 & & 11 \\
\hline \multicolumn{2}{c}{$\boldsymbol{\xi}^{*}$} & 0.0622901 & & & \\
\hline Consistency Ratio & 0.0128 & & &
\end{tabular}

\section{Conclusions and proposed policies}

Today, a phenomenon called medical tourism is of the most growing sectors of the tourism industry in the world and is known as one of the most attractive industries in economic and employment fields, introducing cultures and also creating political benefits the countries. Yazd province of Iran, by having potential capacities in tourism as well as medicine and treatment, can become one of the Asian medical tourism poles by optimal use of these capacities. But so far, this scope of business has not been formed coherently and organized in Yazd province. Hence, in this study, medical tourism situation in Yazd province has been examined and development strategies using SWOT matrix is formulated and finally formulated strategies were ranked using BWM technique and the results were described in detail in previous section. This section includes suggestions which have been set based on main objective of this study for the development of medical tourism in the Yazd province as follows:

- Construction of medical tourism companies or encouragement of private sector to do so,

- Creation of medical tourism exhibitions in other provinces to inform their people of the Medical and Tourism capabilities of Yazd province,

- Preparation of various programs, addressing issues related to medical tourism and promoting this type of tourism in TV and local newspapers to attract medical tourists, satellite advertisements to introduce medical tourism capabilities and familiarize people with the price and quality of medical and tourism services in Yazd, development of information and marketing systems, creation of websites related to medical tourism for patients' access to information, because most medical tourists search their needs via the Internet, Preparation of comprehensive plan for medical tourism in Yazd.

In general, according to obtained results, the following suggestions can be provided:

- Developing medical tourism services standards by specialized firms providing tourism services,

- Communication of private foreign companies with sale and distribution channel including acceptance of foreign insurance,

- Creating a system in Yazd province to register and control foreign patients and their aftertreatment services by medical tourism centers,

- Creating an extensive network of marketing and sales, 
- Designing an accurate cycle for entry and exit of medical tourism,

- Creating medical tourism representative in countries of target market,

- Training staff related to foreign patients in accordance with international approvals.

\section{References}

Arslan, O., \& Er, I. D. (2008). SWOT analysis for safer carriage of bulk liquid chemicals in tankers. Journal of Hazardous Materials, 154(1-3), 901-13. http://doi.org/10.1016/j.jhazmat.2007.10.113

Beladi, H., Chao, C.-C., Ee, M. S., \& Hollas, D. (2015). Medical tourism and health worker migration in developing countries. Economic Modelling, 46, 391-396.

Chaghooshi, A., Arab, A., \& Dehshiri, S. (2016). A fuzzy hybrid approach for project manager selection. Decision Science Letters, 5(3), 447-460.

Cormany, D., \& Baloglu, S. (2011). Medical travel facilitator websites: An exploratory study of web page contents and services offered to the prospective medical tourist. Tourism Management, 32(4), 709-716.

Crooks, V. A., Turner, L., Snyder, J., Johnston, R., \& Kingsbury, P. (2011). Promoting medical tourism to India: Messages, images, and the marketing of international patient travel. Social Science \& Medicine, 72(5), 726 732.

Dalstrom, M. (2013). Medical travel facilitators: connecting patients and providers in a globalized world. Anthropology \& Medicine, 20(1), 24-35.

Dereli, C. (2007). The developing environment for strategy formation in the smaller local authority. International Journal of Public Sector Management, 20(5), 366-379. http://doi.org/10.1108/09513550710772495

Ganguli, S., \& Ebrahim, A. H. (2017). A qualitative analysis of Singapore's medical tourism competitiveness. Tourism Management Perspectives, 21, 74-84.

Garcia, A. G., \& Besinga, C. A. (2006). Challenges and opportunities in the Philippine medical tourism industry. The SVG Review, 41-55.

Ghaffari, S., Arab, A., Nafari, J., \& Manteghi, M. (2017). Investigation and evaluation of key success factors in technological innovation development based on BWM. Decision Science Letters, 6(3), 295-306.

Kangas, B. (2010). Traveling for medical care in a global world. Medical Anthropology, 29(4), 344-362.

Kazemi, Z. (2007). Study of effective factors for attracting medical tourist in Iran. Research Paper Requirements for the MS Degree, Lulea University of Technology, Netherlands.

Khan, S., \& Alam, M. S. (2014). Kingdom of Saudi Arabia: A potential destination for medical tourism. Journal of Taibah University Medical Sciences, 9(4), 257-262.

Mohaghar, A. , Sahebi, I. , Arab, A. (2017). Appraisal of humanitarian supply chain risks using best-worst method. International Journal of Social, Behavioral, Educational, Economic, Business and Industrial Engineering, 11(2), 309 - 314.

Rezaei, J. (2015a). Best-worst multi-criteria decision-making method. Omega, 53, 49-57.

Rezaei, J. (2015b). Best-worst multi-criteria decision-making method: Some properties and a linear model. Omega, 64, 126-130.

Rezaei, J., Nispeling, T., Sarkis, J., \& Tavasszy, L. (2016). A supplier selection life cycle approach integrating traditional and environmental criteria using the best worst method. Journal of Cleaner Production, 135, $577-$ 588.

Rezaei, J., Wang, J., \& Tavasszy, L. (2015). Linking supplier development to supplier segmentation using Best Worst Method. Expert Systems With Applications, 42(23), 9152-9164.

Smith, P. C., \& Forgione, D. A. (2007). Global outsourcing of healthcare: a medical tourism decision model. Journal of Information Technology Case and Application Research, 9(3), 19-30.

Stonehouse, G., \& Pemberton, J. (2002). Strategic planning in SMEs - some empirical findings. Management Decision, 40(9).

Woodman, J. (2009). Patients beyond borders: Everybody's guide to affordable, world-class medical travel. Healthy Travel Media.

Yüksel, İ., \& Dağdeviren, M. (2007). Using the analytic network process (ANP) in a SWOT analysis - A case study for a textile firm. Information Sciences, 177(16), 3364-3382.

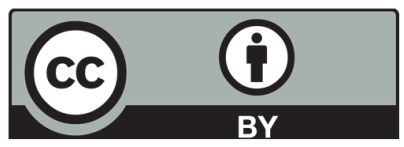

(C) 2018 by the authors; licensee Growing Science, Canada. This is an open access article distributed under the terms and conditions of the Creative Commons Attribution (CC-BY) license (http://creativecommons.org/licenses/by/4.0/). 